\title{
12 år med Noe å lære av i Tidsskriftet
}

\section{Sammendrag}

Bakgrunn. Noe å lære av er en spalte i Tidsskriftet som inneholder pedagogiske kasuistikker ledsaget av en ekspertkommentar. Den har eksistert siden 1999. Hensikten med denne artikkelen er å beskrive pasientene og forfatterne i spalten.

Materiale og metode. Studien er basert på elektroniske søk i Tidsskriftets nettarkiv (2000-11), supplert med manuelt søk i papirutgaven (1999). Medisinsk spesialitet for forfatterne ble definert ut fra arbeidssted.

Resultater. 157 kasuistikker og 157 ledsagende kommentarer ble identifisert. Av de 157 pasientene var det 84 kvinner (54\%). Hyppigste alderskategori var 51-60 år (spredning 0-90 år). Førsteforfatter var oftest tilknyttet indremedisinske avdelinger med tilhørende grenspesialiteter (34\%), så kom nevrologi (13\%), generell kirurgi med grenspesialiteter (11\%) og barnesykdommer (10\%). Parakliniske fag var hovedsakelig representert ved medforfatterskap, hyppigst ved patologi og radiologi. Av totalt 676 forfatterskap var kun sju $(1,0 \%)$ tilknyttet psykiatri og fem $(0,7 \%)$ allmennmedisin.

Fortolkning. Spalten Noe å lære av har gjennom 12 år illustrert et bredt spekter av pasienter, men de medisinske spesialitetene er ujevnt representert. Det kan være ønskelig med flere artikler utgått fra bl.a. psykiatri og allmennmedisin.

\section{Erlend T. Aasheim}

erlend.aasheim@legeforeningen.no Tidsskrift for Den norske legeforening og

Department of Public Health and Primary Care University of Cambridge

England

Kasuistiske pasientbeskrivelser har hatt stor betydning for utviklingen av klinisk medisin og hadde tidligere en sentral plass innen medisinsk publisering. Denne tradisjonen gjelder også for Norge $(1,2)$. Har den anek- dotiske pasienthistorien fortsatt en plass i dagens kunnskapsbaserte medisin?

Randomiserte studier og metaanalyser gir det beste grunnlaget for kliniske behandlingsretningslinjer. Dette innebærer at kasuistikken spiller en mindre rolle i medisinsk publisering. Men det er flere gode grunner til at kasuistikker fortsatt bør publiseres. Thalidomidsaken viste hvordan enkeltobservasjoner kan endre klinisk praksis (3). For medikamenter trukket fra markedet i Spania i perioden 1990-99 av hensyn til pasientsikkerheten var kasuistiske rapporter den viktigste informasjonskilden i 18 av 22 tilfeller (4). Kasuistikker har en intuitiv appell og fanger leserens interesse på en annen måte enn metaanalyser. De spiller dessuten en viktig rolle for leger under utdanning (5).

I Tidsskriftet er det siden 1999 publisert kasuistikker som pedagogiske pasienthistorier, ledsaget av en ekspertkommentar, i spalten Noe å lære av (6). Hovedpoenget med disse kasuistikkene er ikke å presentere sjeldne tilstander, men å fremme god klinisk medisinsk tankegang (2). I en leserundersøkelse i 2007 ønsket mange av Tidsskriftets lesere flere kasuistikker (7).

For et generelt medisinsk tidsskrift bør kasuistikker over tid representere et mangfold av pasienter og fagområder. Skjer dette i praksis? Hva slags pasienter er det som beskrives, og i hvilken grad er de ulike medisinske spesialitetene representert? Da spalten ble innført, så man for seg en stafett fra sykehus til sykehus over hele landet, også utenfor universitetssykehusene (6). I hvilken grad er denne ambisjonen nådd? I denne studien er pasienter i og forfattere av 157 kasuistikker og ekspertkommentarer i spalten Noe å lære av publisert i perioden 1999-2011 kartlagt.

\section{Materiale og metode}

Relevante artikler ble identifisert på www.tidsskriftet.no med søket «Noe å lære av» og avansert søk-funksjonen «Med den nøyaktige setningen». Etter gjentatte søk var 339 artikler publisert i perioden 10.6. 2000-13.12. 2011 identifisert. Artikler ble ekskludert hvis de var publisert $i$ andre spalter $(n=42)$, var engelske oversettelser $(n=6)$ eller omtalte en større pasientgruppe $(n=1)$. De øvrige artiklene var norskspråklige kasuistikker $(\mathrm{n}=145)$ med ledsagende kommentarer $(n=145)$. Manuelt søk i Tidsskriftets papirutgave for 1999 identifiserte ytterligere 12 relevante kasuistikker med ledsagende kommentarer.

For pasientene som var omtalt i artiklene ble det registrert data om hoveddiagnose, kjønn, svangerskap og alderskategori (0-1 år, 2-10 år, 11-20 år, 21-30 år osv.). For artikler der flere pasienter med samme hoveddiagnose ble beskrevet $(\mathrm{n}=2)$, ble kun data om første pasient benyttet.

For forfatterne ble alle arbeidsmessige tilknytninger registrert. Hver forfatter ble klassifisert etter geografisk tilhørighet (ett av 19 fylker) og medisinsk spesialitet (én av 44 spesialiteter). Klassifisering til spesialitet ble gjort med utgangspunkt i forfatterens primære arbeidssted. Når arbeidsstedet indikerte grenspesialitet (f.eks. «Hjerteavdelingen»), ble grenspesialiteten registrert, ikke hovedspesialitet. Ved tvil om spesialitet ble informasjon om ev. sekundært arbeidssted benyttet. Ved fortsatt tvil ble det gjort et orienterende søk på forfatterens navn i Google fulgt av målrettet søk blant godkjente spesialister på Legeforeningens nettside www.legeforeningen.no. Ved fortsatt tvil ble forfatteren klassifisert til «ukjent spesialitet» $(n=4)$. For arbeidssteder med ordet «akuttmedisin» i navnet ble det gjort søk på forfatterens navn blant godkjente spesialister i anestesiologi, hjertesykdommer, indremedisin og psykiatri; forfattere som ikke sto oppført under noen av disse ble klassifisert til anestesiologi. To forfattere ble klassifisert som psykologer, to som cand.real.-er, én som tannlege og én som farmasøyt.

\section{Resultater}

Gjennom litteratursøk ble totalt 157 kasuistikker med 157 ledsagende kommentarer publisert i Noe å lære av i den aktuelle perioden identifisert. Etter opprettelsen av spalten i april 1999 ble det samme år publisert 12 kasuistikker. Antallet falt deretter til ingen kasuistikker i 2003, etterfulgt av en økning til en topp på 23 kasuistikker i årene 2007 og 2008 (e-fig 1).

Av de 157 pasientene var det $54 \%$ kvinner. Hyppigste alderskategori var 51-60 år. Hos

\section{Hovedbudskap}

- Noe å lære av inneholder pedagogiske pasienthistorier ledsaget av en ekspertkommentar

- En gjennomgang viser at et mangfold av pasienter er beskrevet i spalten

- Flere bidrag fra allmennmedisin og psykiatri vil kunne tilføre spalten verdifulle perspektiver 


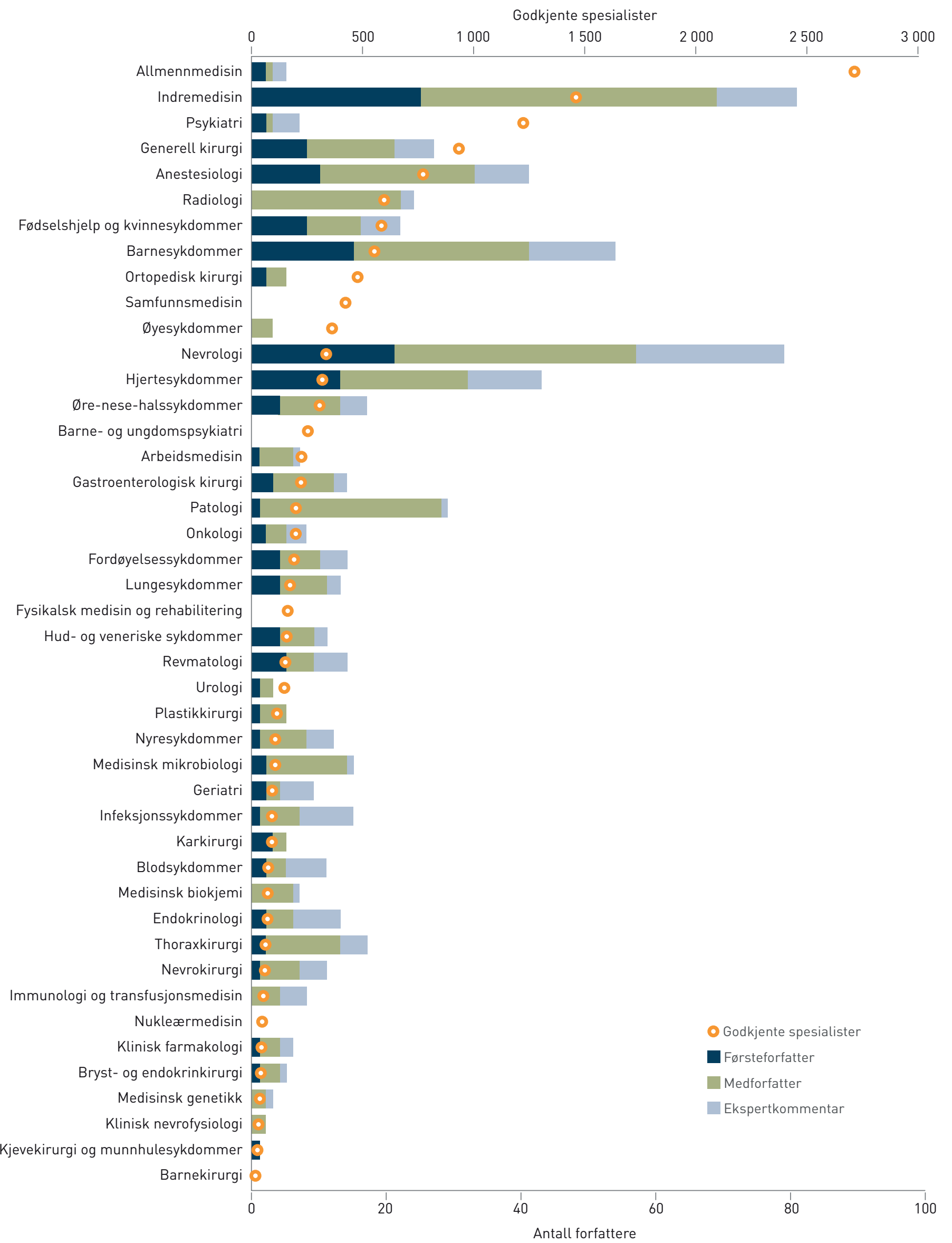

Figur 2 Medisinsk spesialitet for 676 forfattere i spalten Noe å lære av, sammenholdt med totalt antall godkjente spesialister i Norge (8) 


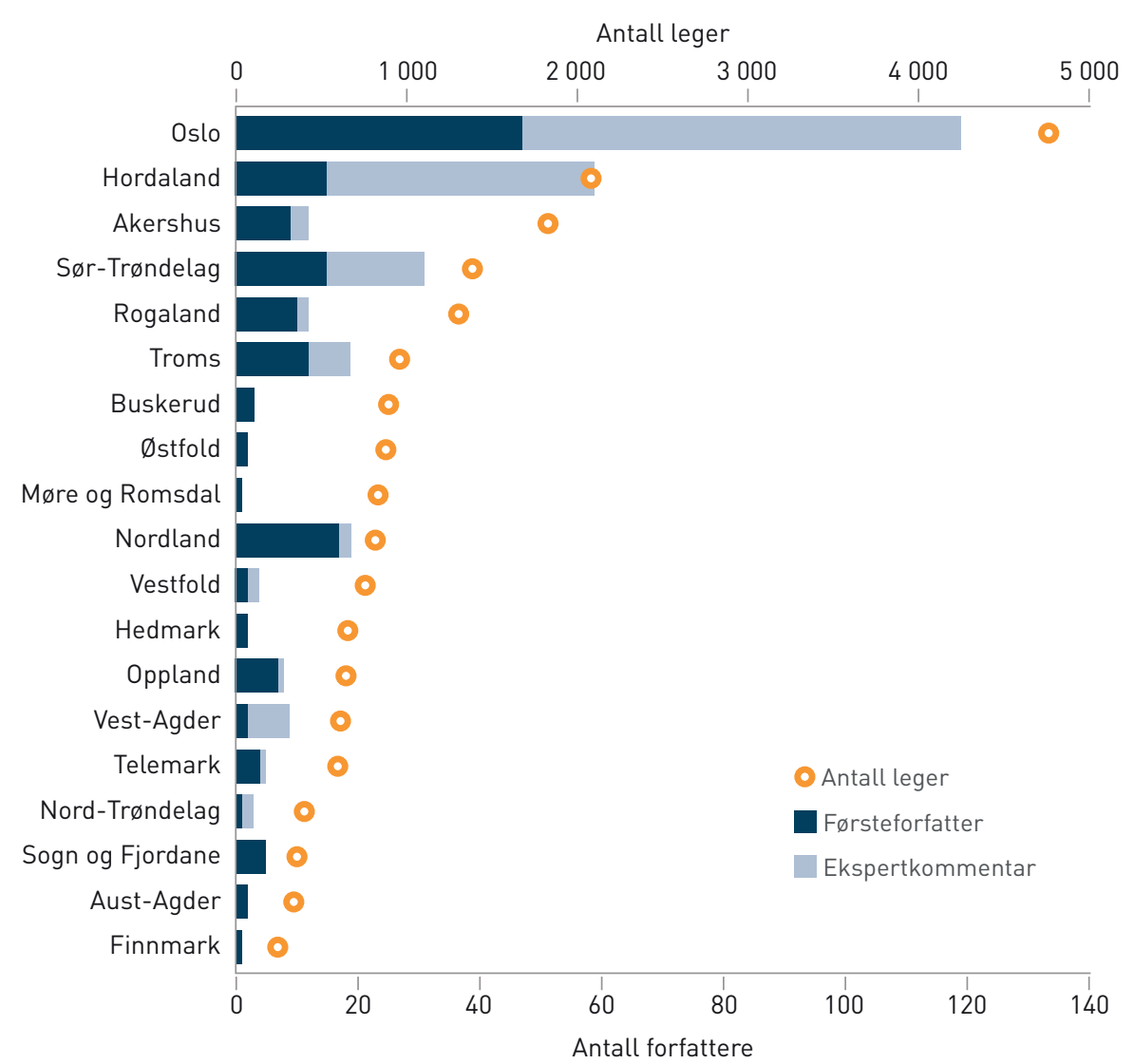

Figur 3 Fylkesmessig tilknytning for forfattere i spalten Noe å lære av, sammenholdt med totalt antall leger ifylkene (9)

kvinnene ble 13 svangerskap omtalt. De fleste hoveddiagnosene var gjenstand for kun én kasuistikk, med unntak av tre artikler om endokarditt og to artikler hver om amyloidose, dermatomyositt, Kawasakis sykdom, leishmaniasis, nephropatia epidemica og tuberkulose.

Artiklene var skrevet av til sammen 676 forfattere, fordelt på 157 førsteforfattere og 359 medforfattere av kasuistikker og 160 forfattere av ledsagende kommentarer. Kasuistikkene hadde median tre forfattere (spredning 1-7). Alle kommentarer, unntatt tre med to forfattere, hadde én forfatter.

\section{Medisinske spesialiteter}

De 157 førsteforfatterne var oftest tilknyttet indremedisin med tilhørende grenspesialiteter $(n=54)$. Deretter fulgte nevrologi $(n=21)$, generell kirurgi med grenspesialiteter $(\mathrm{n}=18)$, barnesykdommer $(\mathrm{n}=15)$ og anestesiologi $(\mathrm{n}=10)$. De parakliniske spesialitetene var sjeldnere representert og da hovedsakelig ved medforfatterskap. Hyppigst representert var patologi $(n=27)$ og radiologi $(n=22)$.

I forhold til antall godkjente spesialister (8) hadde nevrologi flest forfatterskap (fig 2). De store spesialitetene allmennmedisin og psykiatri var svakt representert og bidro med henholdsvis fem og sju av 676 forfatterskap.

\section{Fylker}

Flest førsteforfatterskap utgikk fra Oslo $(\mathrm{n}=47)$, Nordland $(\mathrm{n}=17)$ og Hordaland $(n=15)$. I forhold til antall leger i hvert fylke (9) hadde Nordland, Sogn og Fjordane og Troms flest førsteforfatterskap (fig 3). Ledsagende kommentarer (som redaksjonen inviterer til) utgikk oftest fra Hordaland, Oslo og Sør-Trøndelag, både med og uten justering for antall leger i hvert fylke.

\section{Diskusjon}

Denne studien viser at Tidsskriftets spalte Noe å lære av gjennom 12 år har presentert et bredt spekter av pasienter og diagnoser, men at spesialitetene har vært ujevnt representert. En dominans av nevrologiske problemstillinger passer med mønsteret for kasuistikker publisert i The Lancet (10). At kliniske spesialiteter har flest førsteforfattere av kasuistikker er ikke uventet, men det er påfallende at så få kasuistikker er hentet fra psykiatri og allmennmedisin. Primærhelsetjenesten er tidligere blitt oppfordret til å bidra til spalten (2), men funnene gir grunn til å sende samme oppfordring også til andre spesialiteter.

Det at fem eller seks spesialiteter er representert på én forfatterliste $(11,12)$, tyder på et imponerende tverrfaglig samarbeid. Trolig bør alle som har vært aktivt involvert i utredningen og behandlingen av en pasient, informeres før en kasuistikk innsendes for publisering. Det er blitt påpekt at radiologer og andre faggrupper ikke alltid er med i forfatterlisten når en kasuistikk publiseres, selv om de har bidratt vesentlig i utredningen og behandlingen av pasienten (13).

Antall forfatterskap i fylkene varierte, men alle fylkene var representert. Dette er spesielt interessant, ettersom den opprinnelige ordningen med å invitere bidrag til Noe å lære av (6) raskt falt sammen (2). Det er verdt å merke seg at innsatsen fra enkeltindivider ga utslag på spesialitets- og fylkesnivå: Erik Waage Nielsen (anestesiolog i Bodø) og Odd Kildahl-Andersen (indremedisiner i Harstad) har forfattet henholdsvis ti og åtte kasuistikker i spalten. Dette er en imponerende innsats $i$ en tid da kasuistikkartikler kan gi mindre akademisk meritt enn originalartikler.

Studien har flere begrensninger. Forfattere med tilknytning til en gitt spesialitet, f.eks. allmennmedisin, kan ha skrevet en kasuistikk mens de hadde tjeneste i en annen spesialitet, f.eks. indremedisin, uten at dette er fanget opp. De aller fleste manuskriptene er innsendt spontant i stort sett hele studieperioden, mens ekspertkommentarene er invitert av redaksjonen. Det forelå ikke informasjon om refuserte manuskripter. Det er derfor uvisst om de publiserte kasuistikkartiklene er representative for alle kasuistikkmanuskripter som sendes inn til vurdering for publisering.

e-fig 1 finnes kun i Tidsskriftets nettutgave.

\section{Erlend T. Aasheim (f. 1974)}

er lege med ph.d., medisinsk redaktør i Tidsskriftet og Academic Clinical Fellow ved Department of Public Health and Primary Care, University of Cambridge, England.

Ingen oppgitte interessekonflikter.

\section{Litteratur}

1. Hem E. Enkeltpasienter som læremestre. Tidsskr Nor Lægeforen 2007; 127: 561

2. Wyller TB. Kasuistikker for det 21. århundre. Tidsskr Nor Lægeforen 2004; 124: 1913.

3. Mcbride WG. Thalidomide and congenital abnormalities. Lancet 1961: 278: 1358

4. Arnaiz JA, Carné X, Riba $\mathrm{N}$ et al. The use of evidence in pharmacovigilance. Case reports as the reference source for drug withdrawals. Eur J Clin Pharmacol 2001; 57: 89-91.

5. Vandenbroucke JP. In defense of case reports and case series. Ann Intern Med 2001; 134: $330-4$

6. Gulbrandsen P. Noe vi lærte av er noe å skrive om Tidsskr Nor Lægeforen 1999; 119: 1265-6.

7. Aasland OG. Tidsskriftets leserundersøkelse 2007. Tidsskr Nor Legeforen 2008; 128: 1512-4.

8. Den norske legeforening. Godkjente spesialister per 13.4.2011. www.legeforeningen.no/id/171362 (6.1.2012).

9. Den norske legeforening. Alle legemedlemmer fordelt på fylkesavdeling og yrkesforening per 3.9.2007. www.legeforeningen.no/id/99171 (6.1.2012).

10. Kang S. Anecdotes in medicine -15 years of Lancet case reports. Lancet 2010; 376: 1448-9.

11. Zätterstrøm UK, Hokland BM, Walberg M et al. En halsinfeksjon med rask forverring. Tidsskr Nor Lægeforen 2002; 122: 1896-9.

12. Moser KH, Rødevand E, Hammerstrøm J et al. En tidligere frisk mann med feberepisoder med kirkespirforløp. Tidsskr Nor Legeforen 2008; 128 : 1845-7.

13. Stiris MG. Fortsatt noe å lære av? Tidsskr Nor Lægeforen 2007; 127: 1234.

Mottatt 24.10. 2011, første revisjon innsendt 13.11 2011, godkjent 1.12. 2011. Medisinsk redaktør Petter Gjersvik. 